\title{
The relationship between self-reported habitual exercise and visual field defect progression: a retrospective cohort study
}

\author{
Satoshi Yokota ${ }^{1,2}$, Yuji Takihara ${ }^{1}$, Kanako Kimura ${ }^{1}$, Yoshihiro Takamura ${ }^{1}$ and Masaru Inatani ${ }^{1 *}$
}

\begin{abstract}
Background: Exercise reduces intraocular pressure (IOP) in the short term. However, it is not known whether exercise contributes to slower glaucomatous visual field defect progression.

Methods: Twenty-four primary open-angle glaucoma or exfoliation glaucoma patients who were evaluated by the Humphrey Field Analyzer (HFA) 24-2 program $\geq$ four times in 3 years were enrolled. Patients with a history of intraocular surgery in past 3 years or other eye diseases threatening visual fields were excluded. Patients were classified into two groups whether they had exercise habits or not.

Results: Eleven patients had exercise habits. The mean \pm standard error of IOP and MD slope were $14.8 \pm 0.9 \mathrm{mmHg}$ and $+0.20 \pm 0.20 \mathrm{~dB} /$ year in the exercise group and $13.3 \pm 0.8 \mathrm{mmHg}$ and $-0.53 \pm 0.18 \mathrm{~dB} /$ year in the non-exercise group ( $P=0.24$ and $P=0.01$, respectively). Higher IOP [odds ratio $(\mathrm{OR})=0.44 / 1 \mathrm{mmHg}$ increase; $P=0.02$ ] and habitual exercise $(O R=0.04 ; P=0.02)$ reduced the visual field defect progression risk in logistic regression analyses.

Conclusions: Patients with self-reported exercise habits had slower glaucoma progression.

Keywords: Self-reported habitual exercise, Glaucoma, Visual field defect

Abbreviations: HFA, Humphrey field analyzer; IOP, Intraocular pressure; logMAR, Logarithm of the minimum angle of resolution; MD, Mean deviation; OR, Odds ratio; SITA, Swedish interactive thresholding algorithm
\end{abstract}

\section{Background}

Pathogenesis of glaucoma, the leading cause of irreversible blindness worldwide, is related to intraocular pressure (IOP) [1]. Systemic factors-blood flow, intracranial pressure, and migraine-and lifestyle or environmental factors are associated with primary open-angle glaucoma [2]. Smoking and occupational exposure to pesticides increases glaucoma risk; whereas consumption of fruits and vegetables and omega- 3 fatty acid are associated with lower glaucoma risk [2, 3].

Although exercise lowers IOP, the exact mechanism remains unclear [4]. Exercise intensity is related to glaucoma prevalence. For example, faster $10-\mathrm{km}$ race performance predicted lower glaucoma risk [5]. However, the

\footnotetext{
* Correspondence: inatani@u-fukui.ac.jp

1Department of Ophthalmology, Faculty of Medical Sciences, University of Fukui, Japan, 23-3 Matsuokashimoaizuki, Eiheiji, Yoshida, Fukui 910-1193, Japan

Full list of author information is available at the end of the article
}

relationship between exercise and visual field defect progression remains unknown. We examined the relationship between self-reported habitual exercise and visual field defect progression to determine exercise use in glaucoma patients.

\section{Methods}

Patient selection

All patients visited the Department of Ophthalmology, University of Fukui Hospital, between August 2014 and March 2015 and met all inclusion criteria:

1. Primary open-angle glaucoma or exfoliation glaucoma.

2. Four or more visual field tests using the Humphrey Field Analyzer (HFA) Swedish interactive thresholding algorithm (SITA) standard 24-2 program (Carl-Zeiss Meditec Co Ltd, Tokyo, Japan) during the previous 3 years. 
Exclusion criteria:

1. Eyes that underwent ocular surgery, including antivascular endothelial growth factor injection during the previous 3 years.

2. Eyes with other ocular diseases influencing the perimetry in the short-term (e.g., vitreous hemorrhage and corneal ulcer).

If both eyes met the criteria, one eye was randomly selected using a random number table.

\section{Self-reported exercise habits}

Patients were classified into two groups by a single selfreporting questionnaire: "Do you have habitual exercise more than 30 min per week?" Patients were classified into the exercise and non-exercise group based on their answers.

\section{Patient data extraction}

Patient data were retrospectively reviewed from their clinical records. Mean deviation (MD) of HFA, IOP, and decimal visual acuity were extracted from their clinical records.

\section{Visual field testing}

SITA standard 24-2 perimetry program with HFA was used for visual field testing. Reliable tests were defined as those with $<30 \%$ fixation losses and false-positive or -negative responses. From the result of visual field test, MD slope was calculated by HfaFiles (Beeline Co Ltd, Tokyo, Japan). Visual filed defect progression was defined as MD slope worse than $-0.50 \mathrm{~dB} /$ year [6].

\section{Primary and secondary outcome}

Primary outcome was the comparison of MD slope between the exercise and non-exercise group. Secondary outcomes included IOP, MD at last visit, and visual acuity. Decimal visual acuity was converted to logarithm of the minimum angle of resolution (logMAR) for statistical analyses.

\section{Statistical analyses}

Univariate comparisons were performed using the twosided student's $t$-test for continuous variables and the Fisher's exact test for categorical variables. Prognostic factors for visual field defect progression were determined by logistic regression analysis. $P$-value $\leq 0.05$ was considered statistically significant.

\section{Results}

\section{Primary and secondary outcome measures}

Of 24 patients who met the criteria, 11 and 13 patients were classified into the exercise and non-exercise groups, respectively. Patient backgrounds are summarized in Table 1. IOP, logMAR, and MD at the last visit were 14.8
Table 1 Patient backgrounds in the exercise group and nonexercise group

\begin{tabular}{|c|c|c|c|}
\hline & $\begin{array}{l}\text { Exercise group } \\
(n=11)\end{array}$ & $\begin{array}{l}\text { Non-exercise group } \\
(n=13)\end{array}$ & $P$-value \\
\hline Male/female & $6 / 5$ & $3 / 10$ & $0.21^{\mathrm{b}}$ \\
\hline Age (years) ${ }^{a}$ & $68.5 \pm 10.9$ & $69.1 \pm 11.9$ & $0.91^{c}$ \\
\hline IOP $(\mathrm{mmHg})^{\mathrm{a}}$ & $14.8 \pm 0.9$ & $13.3 \pm 0.8$ & $0.24^{c}$ \\
\hline $\log M A R^{a}$ & $0.08 \pm 0.04$ & $0.08 \pm 0.04$ & $0.93^{c}$ \\
\hline $\mathrm{MD}(\mathrm{dB})^{\mathrm{a}}$ & $-8.22 \pm 1.69$ & $-8.45 \pm 1.55$ & $0.92^{c}$ \\
\hline $\begin{array}{l}\text { The number of } \\
\text { anti-glaucoma drugs }\end{array}$ & $2.5 \pm 0.4$ & $2.2 \pm 0.4$ & $0.58^{c}$ \\
\hline Type of glaucoma & & & $0.58^{\mathrm{b}}$ \\
\hline $\begin{array}{l}\text { Primary open-angle } \\
\text { glaucoma }\end{array}$ & 9 (81.8\%) & 12 (92.3 \%) & \\
\hline Exfoliation glaucoma & $2(18.2 \%)$ & $1(7.7 \%)$ & \\
\hline
\end{tabular}

$M D$ mean deviation, LogMAR logarithm of the minimum angle of resolution ${ }^{\mathrm{a}}$ Mean \pm standard deviation; ${ }^{\mathrm{b}}$ Fisher's exact test; ${ }^{\mathrm{C}}$ Student's t-test

$\pm 0.9 \mathrm{mmHg}, 0.08 \pm 0.04$, and $-8.22 \pm 1.69 \mathrm{~dB}$ in the exercise group and $13.3 \pm 0.8 \mathrm{mmHg}, 0.08 \pm 0.04$ and $-8.45 \pm$ $1.55 \mathrm{~dB}$ in the non-exercise group. No significant differences in IOP $(P=0.24)$, logMAR $(P=0.93)$, or $\mathrm{MD}(P=$ $0.92)$ at the last visit were observed. The number of antiglaucoma medications was $2.5 \pm 0.4$ and $2.2 \pm 0.4$ in the exercise and non-exercise groups, respectively. No significant differences were observed between the groups in the number of anti-glaucoma medications $(P=0.58)$.

MD slope in the exercise and non-exercise group was $+0.20 \pm 0.20$ (mean \pm standard error) $\mathrm{dB} /$ year and $-0.53 \pm$ $0.18 \mathrm{~dB} /$ year. Non-exercised group experienced faster visual field defect progression $(P=0.01)$. During the observational period, 8/11 (72.7 \%) and 7/13 (53.8\%) patients experienced escalation of anti-glaucoma therapy. No significant differences were observed between the groups in escalation of anti-glaucoma therapy $(P=0.42$; Table 2$)$.

\section{Prognostic factors for visual field defect progression}

Age; sex; IOP; logMAR; MD; number of anti-glaucoma medications at last visit; escalation in anti-glaucoma therapy during the observational period; and self-reported exercise habits were evaluated as possible factors for visual field defect progression. In univariate logistic regression models (Table 3), two factors were statistically significant.

Table 2 Patient outcomes in the exercise group and non-exercise group in past 3 years

\begin{tabular}{llll}
\hline & $\begin{array}{l}\text { Exercise group } \\
(n=11)\end{array}$ & $\begin{array}{l}\text { Non-exercise group } \\
(n=13)\end{array}$ & $P$-value \\
\hline MD slope (dB/year) ${ }^{\mathrm{a}}$ & $0.20 \pm 0.20$ & $-0.53 \pm 0.18$ & $0.01^{* \mathrm{~b}}$ \\
$\begin{array}{l}\text { Escalation of } \\
\text { anti-glaucoma therapy }\end{array}$ & $8 / 11(72.7 \%)$ & $7 / 13(53.8 \%)$ & $0.42^{c}$ \\
\hline${ }^{*} P<0.05$ & & \\
${ }^{a}$ Mean \pm standard error; ${ }^{b}$ Student's $t$-test; ${ }^{\text {C }}$ Fisher's exact test &
\end{tabular}


Table 3 Risk factors for visual field defect progression by logistic regression analyses

\begin{tabular}{|c|c|c|c|c|}
\hline & \multicolumn{2}{|l|}{ Univariate } & \multicolumn{2}{|l|}{ Multivariate } \\
\hline & OR $(95 \% \mathrm{Cl})$ & $P$-value & OR (95\% Cl) & $P$-value \\
\hline Age (years) ${ }^{a}$ & $0.98(0.91-1.06)$ & 0.62 & $1.06(0.92-1.29)$ & 0.41 \\
\hline $\operatorname{Sex}(M / F)$ & $0.91(0.17-4.88)$ & 0.92 & $3.02(0.19-104.7)$ & 0.44 \\
\hline IOP $(\mathrm{mmHg})^{\mathrm{a}}$ & $0.56(0.27-0.85)$ & $0.003^{*}$ & $0.44(0.11-0.92)$ & $0.02^{*}$ \\
\hline${\log M A R^{a}}$ & $1.54(0.001-1829.0)$ & 0.90 & $192.4\left(0.003-3.08 \times 10^{8}\right)$ & 0.34 \\
\hline $\mathrm{MD}(\mathrm{dB})^{\mathrm{a}}$ & $0.92(0.77-1.07)$ & 0.28 & $1.01(0.67-1.45)$ & 0.97 \\
\hline Habitual exercise & $0.10(0.01-0.59)$ & $0.01^{*}$ & $0.04(0.0003-0.70)$ & $0.02^{*}$ \\
\hline Number of anti-glaucoma drugs ${ }^{a}$ & $0.66(0.33-1.23)$ & 0.20 & $0.46(0.07-1.61)$ & 0.23 \\
\hline Escalation of anti-glaucoma therapy & $0.53(0.09-2.83)$ & 0.46 & $0.58(0.02-14.36)$ & 0.72 \\
\hline
\end{tabular}

$O R$ odds ratio, $C l$ confidence interval, IOP intraocular pressure, LogMAR logarithm of the minimum angle of resolution, $M D$ mean deviation ${ }^{*} P<0.05$

${ }^{\mathrm{a}}$ Per $1 \mathrm{mmHg}$ increase

Higher IOP and habitual exercise were found to be associated with visual field defect progression [odds ratio $(\mathrm{OR})=0.56 ; P=0.003$ per $1 \mathrm{mmHg}$ increase and $\mathrm{OR}=0.10 ; P=0.01$, respectively]. Significant predictors of visual field defect progression by multivariable logistic regression analysis (Table 3 ) were higher IOP $(\mathrm{OR}=0.44$ per $1 \mathrm{mmHg}$ increase; $P=0.02)$ and habitual exercise $(\mathrm{OR}=0.04 ; P=0.02)$.

\section{Discussion}

Exercise reduced IOP [4]. Changes in colloid osmotic pressure (a factor in capillary fluid exchange); increases in plasma osmolarity, ocular blood flow, and blood lactate; and decreases in blood $\mathrm{pH}$ have all been suggested as possible mechanisms that initiate a reduction in IOP. The exact mechanism is not elucidated. However, in this study, self-reported habitual exercise had no effect on IOP. This is probably due to small sample size. Glaucoma incidence was related to physical activity in a cohort of 29,854 male runners [5]. However, no other studies showed a relationship between exercise and glaucomatous visual field defect progression in glaucoma patients. Thus, we believe that this study is the first to demonstrate a relationship between exercise and visual field loss progression in glaucoma patients.

Here high IOP was related to slower visual field loss progression, which is in contrast with previous reports [7]. In clinical settings, patients with rapidly advanced visual field defect tend to receive more intensive treatments with lower IOP targets. This clinical decision may contribute to lower IOP in progressing patients. Prospective and large-scale studies are required to fully elucidate the relationship between IOP and visual field loss progression. Although the mechanism underlying the effect of exercise in deteriorating visual field loss progression remains unknown, exercise was shown to be beneficial for vascular profiles [8]: The smaller preresistance and resistance vessels are involved in younger individuals, whereas the large elastic arteries are involved in older individuals. Active individuals had a lower risk of low ocular perfusion pressure [9]. These studies indicate that exercise may affect disc circulation and attenuate visual field loss.

This study had several limitations. It was a retrospective, single-centered, small sample size study. We evaluated MD slopes to analyze visual field defect progression. Different results may have been obtained with visual field index or point-wise event analysis.

\section{Conclusion}

This study suggested that self-reported habitual exercise is associated with slower visual field progression in open-angle glaucoma patients. It is necessary for larger scale, and prospective cohort study to clarify the relationship between exercise and glaucomatous visual field defects. Even though, it may be clinically beneficial to encourage glaucoma patients to have habitual exercise.

\section{Additional file}

\section{Additional file 1: Analyzed datasets. (XLSX $36 \mathrm{~kb}$ )}

\section{Acknowledgements}

The authors would like to thank Enago (www.enago.jp) for the English language review.

\section{Funding}

This study was supported, in part, by Grants-in-Aid for Scientific Research from the Ministry of Education, Culture, Sports, Science, and Technology (MEXT), Tokyo, Japan.

\section{Availability of data and materials}

The dataset supporting the conclusions of this article is included within the article and its Additional file 1.

Authors' contributions

SY, YT and Ml designed study. SY, YT, KK, and Ml collected data. SY performed statistical analysis. All authors discussed to interpret data. SY and $\mathrm{Ml}$ drafted the manuscript. All authors read and approved the final version of the manuscript. 


\section{Competing interests}

The authors declare that they have no competing interests.

\section{Consent for publication}

Not applicable.

\section{Ethics approval and consent to participate}

All study procedures were approved by the Institutional Review Board of University of Fukui, Japan. Study participants provided informed consent orally before participation.

\section{Author details}

'Department of Ophthalmology, Faculty of Medical Sciences, University of Fukui, Japan, 23-3 Matsuokashimoaizuki, Eiheiji, Yoshida, Fukui 910-1193, Japan. ${ }^{2}$ Department of Ophthalmology and Visual Sciences, Kyoto University Graduate School of Medicine, Japan, Yoshidakonoecho, Sakyo, Kyoto, Kyoto 606-8501, Japan

Received: 25 November 2015 Accepted: 16 August 2016

\section{Published online: 23 August 2016}

\section{References}

1. Weinreb RN, Aung T, Medeiros FA. The pathophysiology and treatment of glaucoma: a review. JAMA. 2014;311:1901-11.

2. Renard JP, Rouland JF, Bron A, et al. Nutritional, lifestyle and environmental factors in ocular hypertension and primary open-angle glaucoma: an exploratory case-control study. Acta Ophthalmol. 2013;91:505-13.

3. Coleman AL, Stone KL, Kodjebacheva G, et al. Glaucoma risk and the consumption of fruits and vegetables among older women in the study of osteoporotic fractures. Am J Ophthalmol. 2008;145:1081-9.

4. Roddy G, Curnier D, Ellemberg D. Reductions in intraocular pressure after acute aerobic exercise: a meta-analysis. Clin J Sport Med. 2014;24:364-72.

5. Williams PT. Relationship of incident glaucoma versus physical activity and fitness in male runners. Med Sci Sports Exerc. 2009;41:1566-72.

6. Komori S, Ishida K, Yamamoto T. Results of long-term monitoring of normaltension glaucoma patients receiving medical therapy: results of an 18-year follow-up. Graefe's Arch Clin Exp Ophthalmol. 2014;252:1963-70.

7. Leske MC, Heijl A, Hyman L, et al. Predictors of long-term progression in the early manifest glaucoma trial. Ophthalmology. 2007;114:1965-72.

8. McDonnell BJ, Maki-Petaja KM, Munnery M, et al. Habitual exercise and blood pressure: age dependency and underlying mechanisms. Am J Hypertens. 2013;26:334-41.

9. Yip JLY, Broadway DC, Luben R, et al. Physical activity and ocular perfusion pressure: the EPIC-Norfolk eye study. Invest Ophthalmol Vis Sci. 2011;52: 8186-92.

\section{Submit your next manuscript to BioMed Central and we will help you at every step:}

- We accept pre-submission inquiries

- Our selector tool helps you to find the most relevant journal

- We provide round the clock customer support

- Convenient online submission

- Thorough peer review

- Inclusion in PubMed and all major indexing services

- Maximum visibility for your research

Submit your manuscript at www.biomedcentral.com/submit
Biomed Central 